\title{
Encounters with Self-Monitoring Data on ICT Use
}

\author{
Minna Saariketo
}

Department of Computer Science, Aalto University, minna.saariketo@aalto.fi

\begin{abstract}
This article elaborates on the prospects for research interventions that repurpose the means of datafication to create possibilities for people to reflect on what it means in their daily lives. The research data consist of qualitative research interviews $(n=13)$ in which media diaries and tracking data from the participants' smartphones and computers served as prompts for reflection. The experiences from the self-monitoring and the encounters with tracked data by self-identified avid ICT users are analysed to gain a better understanding of the kinds of possibilities for reflexivity that are enabled when people have access to data that are rarely available to them.
\end{abstract}

Keywords: datafication, self-monitoring, self-tracking, ICT use, research intervention

\section{Introduction}

People's daily lives have become infused with portable, always-on and networked information and communication technology (ICT) in the 2010s. Data obtained from the use of these devices and from actions and interactions in digitalized environments have become desirable to companies, researchers and users themselves. The status of data in contemporary society is illustrated in estimations that data have bypassed oil as the most valuable resource in the world (e.g. The Economist, 2017). The datafication of our daily lives means that multiple aspects of it, such as friendships, interests, information searches, movements, locations and emotional reactions, are quantified (Mayer-Schönberger \& Cukier, 2013; van Dijck, 2014). After being generated, these data often move autonomously from the users' control (Coté, 2014), they are reconstituted to benefit aggregators in ways that are not transparent and yet they are utilized in ways that affect users' conditions of possibility. According to Andrejevic and Burdon (2015: 19), what is taking place is "a shift from targeted, purposeful, and discrete forms of information collection to always-on, ubiquitous, opportunistic ever-expanding forms of data capture". Couldry and Mejias (2018) term this "data colonialism". Thus, it has become virtually impossible not to leave digital traces of quotidian life.

The intertwinement of these data-driven technologies with the everyday means that the implied values, ideologies and power structures are shaping our social worlds, ac-

Saariketo, M. (2019). Encounters with self-monitoring data on ICT use. Nordicom Review, 40 (Special Issue 1): 125-140. doi:10.2478/nor-2019-0018. 
tions and encounters. In the critical literature, big data and the consequent processes of algorithmic governance have been considered as phenomena that potentially exacerbate power imbalances in the digital era, for instance by eroding privacy, enabling new forms of profiling and social sorting, facilitating anticipatory governance and enhancing control creep (Kitchin \& Laurialt, 2014). The asymmetric relationship between the targets of data mining and those who collect, store and process data has been termed the "big data divide" (Andrejevic, 2014).

Although the research within critical data studies has offered a better understanding of the complex assemblages of data mining, the technical details of infrastructures and processes and the consequences that they have for social life, there is a need to understand better how users experience and make sense of their datafied lives (see also Beer, 2009; Couldry \& Powell, 2014; Michael \& Lupton, 2015). In this article, the question is approached by studying how avid users of ICT encounter self-monitoring data of their ICT use and what kind of possibilities for reflection are hereby enabled. Thus, the article elaborates on the prospects for research interventions that repurpose the means of datafication to create possibilities for people to reflect on what it means in their daily lives. It is a reaction to the call in the field of media studies to investigate the role of media technologies and infrastructures in contemporary social life using innovative methods (e.g. Kubitschko \& Kaun, 2016).

The small-scale pilot reported in this article had thirteen participants, who selfidentified as having an intense relationship with digital technology and with social media especially. The self-monitoring was executed by using freely available trackers that recorded details of smartphone and computer use and by keeping a media diary for seven days. The research data consist of almost twelve hours of qualitative interviews, in which self-tracking data and the media diary were used as prompts for reflection. The research intervention is the first step in the project Digital Face, which evaluates how such tools could possibly be turned into ones that help users to reflect on their relationship with data-saturated practices from a fresh perspective.

The article is organized as follows. The related research, research design and execution of the intervention are discussed in their respective chapters. The outcomes are reflected by reporting the empirical observations through two interrelated themes: encounters with tracked data and evaluations of the tracker. In the conclusion, potential next steps are proposed.

\section{Research into digital traces as a looking glass}

The agentive force of visualized data has been studied in an inspiring way in the emerging field of self-tracking research. Self-tracking (also known as personal analytics or informatics, self-quantification, biomonitoring and lifelogging) refers to a practice in which data are obtained using for example smartphones, activity trackers, wearable devices or other sensors to record, analyse and gain self-knowledge about features of daily life (Lupton, 2016). The discourse around these new data-capturing technologies sometimes gives the impression of being a radically new phenomenon and thus disregards the long tradition of self-monitoring of one's life with the help of diaries and weight scales (Crawford et al., 2015; Ruckenstein, 2014). Still, digital devices have given rise to new means of self-tracking that are also substantially different from the old modes, 
namely regarding who has access to the data generated, with whom they are shared and how value is extracted from them.

Although there is a proliferation of tools to collect, process and display data ranging from financial expenses to driving habits, self-tracking has often been associated with health and wellness and the use of data on, for example, activity, heart rate, calorie consumption and sleep patterns. Globally enthusiastic self-trackers have formed the network called Quantified Self to share and discuss what they have learned from the data that they collect about themselves. In their ethnography on this movement, Nafus and Sherman (2014) pointed out that, regardless of the focus on self-optimization, Quantified Self has been an important site for questioning self-monitoring devices, related data flows and their ownership as well as developing ways of working around the systems of profit-driven data gathering and its algorithmic logics.

Studies within self-tracking research have scrutinized the ways in which tracked data serve as a site for reflection, learning and personal insights. For example, Ruckenstein (2014) explored the encounters with heart rate variability data. Using an ethnographic approach, Sharon and Zandbergen (2017) identified a variety of ways in which members of the Quantified Self movement ascribe value and meaning to their data. For their part, Fiore-Gartland and Neff (2015) mapped the different expectations that people have of data in formal health care and consumer wellness and identified a variety of "data valences". The outcomes of these studies point to the relevance of studying how self-tracking data are appreciated and harnessed for different purposes. The results suggest that data are infused with individual meanings. Their importance is traced back to these unique meanings, which can give value to personal realities and mundane practices. As Ruckenstein (2014) suggested, encounters with tracked data can produce permanence and stability but also profoundly change the manners in which the self, others and daily life are reflected.

Although measuring and tracing aspects of the personal have become more commonplace, tracking the use of ICT has not gained ground to the same extent as self-monitoring the body. Likewise, academic research with a focus on the self-monitoring of ICT devices has been marginal (see Bechmann, 2015). In the research on human-computer interaction (HCI), several studies have tracked data from smart devices, but only rarely has the interest been in how people themselves interpret and make sense of these data, let alone how they consider their relevance to their everyday life. The research by Rooksby and colleagues (2016) was an opening for examining how data on screen time might be of interest to students monitoring their mobile devices and computers. Although the results of the research pointed out that the tracked data were desirable to the participants for goals such as increasing productivity and disciplining or cutting down device use, they did not analyse the way in which these interpretations were interrelated with the daily datafied life of the participants.

In their action research with young coders, Pybus and colleagues (2015) examined ways of understanding and reclaiming the data that are produced on smartphones. The participants were asked to use an app called MobileMiner, which was designed to learn more about the data generated by the devices and applications used. The application worked as a kind of data spy to examine the routine data harvesting by the apps used. The researchers opened up the harvested data to the participants and thus in practice created an alternative infrastructure to proprietary data sets that commonly store data from the use of mobile devices. In hackathons organized as part of the research project, 
the participants were allowed both to develop the functioning of the MobileMiner and to work on their own applications based on observations from the harvested data, demonstrating the potential that lies in giving access to data that are not usually available.

\section{Research design: Self-tracked data and a media diary as a reflective mirror}

So-called privacy mirrors (Nguyen \& Mynatt, 2002), developed within privacy studies in computer science, provided inspiration for the research design in this study. The idea of such a "mirror" is to allow the participant apprehension of such aspects that are not easily accessible otherwise and thus possibly enable new reflexivity. The development of this particular reflective "mirror" was motivated by the observation that, although computer code mediates our everyday spaces, practices and experiences ever more thoroughly, its role in shaping contemporary sociality and public life often passes unnoticed. For example, geographers Thrift and French have conceptualised this process in which computation has sunk as a taken-for-granted, inconspicuous, and opaque part of daily life as "technological unconscious" (Thrift \& French, 2002: 312; see also Thrift, 2004). In the context of data studies, Smith (2018) recently referred to the same phenomenon with the notion "data doxa", that is, the process through which digital data (as well as the devices and platforms that stage data) have become invisible as they have been rendered a normal, necessary and enabling part of Western societies.

As data are never simply neutral, objective and independent but always situated, contingent and relational (Kitchin \& Laurialt, 2014), tracked data cannot serve as a mirror per se. Therefore, the focus of this article is on studying the encounters with self-monitoring data and the possibilities for reflexivity enabled in these encounters. By "encounter" I refer to the insights into, reflections on and processes of interpreting that took place when the participants made sense of the visualizations on the tracked data in the qualitative research interviews and in the media diaries.

The "mirror" was constructed from a combination of a media diary and freely available applications to self-monitor one's use of ICT devices. Although smartphones may include a variety of sensors from accelerometers to gyroscopes and from heart rate sensors to thermometers, they only rarely included applications that let the user observe the patterns of use at the time of the research. ${ }^{1}$ As the use of digital devices is intertwined with many daily chores that often take place without the presence of other people and it is spread throughout the day as moments of use that can be as short as a glance, tracking that takes place in the background affords information on use that is otherwise difficult for people themselves, let alone researchers, to observe and record (Pink \& Fors, 2017).

In the application stores, there are several freely available ICT self-monitoring applications for different operating systems on computers, smartphones and tablets to track which apps are used, how often, for how long and when. On Android devices, the trackers can detail which applications are used and which websites are visited. The iOS applications provide more general informations, such as the overall time spent on the device and the number of pickups. Some information on the application use can be accessed by checking it from the iPhone battery usage details.

The tracking software RescueTime, ManicTime, App Usage and RealizD were chosen as applications for self-monitoring, as they came with a multiplicity of potentially 
interesting visualizations. Utilizing freely available applications provided an overview of what is offered to people in terms of self-monitoring their ICT use. As the tracking applications were not designed by the research group and had their own terms of use, this aspect was included as part of the research intervention. It turned out that the concerns related to data mining and terms of use were more an issue for the researcher than for the participants themselves.

Besides using trackers on their smartphones and computers, the participants were asked to keep a media diary. They were provided with a template for inspiration but allowed freedom in style and format (pen and paper, electronic, etc.). The instruction was to make exact notes of ICT use for one day and to write down important observations on tracked data and routines related to ICT use during the rest of the days. The media diary was an important part of the "mirror", as it enabled the reporting of observations and feelings as well as additional information that was not recorded by the software (e.g. with whom messages were exchanged and why an app was used). It was also used to record information on the use of devices that were not tracked with software, such as game consoles or work computers that had restrictions on software installation.

\section{The research intervention in practice: participants, execution and method of analysis}

The research intervention was executed in two parts so that the observations from the first round could be used to improve the research design and focus attention on specific aspects in the second round. The intervention took place in autumn 2017 in Finland. In the first round, six participants were recruited based on their interest in observing the role of ICT devices in daily life by using self-tracking software and a media diary. They were found through advertisements on social media. All the participants were from the same city on the south-west coast of Finland. Based on the findings from this first round, it was decided that, in the second round, the recruitment of participants would target people who consider networked digital technology, and especially social media platforms, as a central part of their work and free time. This focus was chosen as the intense relations seemed to necessitate negotiations that called for closer attention. Using social media, email advertising to organizations and professional groups hosting potentially relevant participants (e.g. journalists, entrepreneurs and political actors) and snowballing, ten participants were recruited in the second round. They were from around Finland. Of the participants from the first round, three met the criterion chosen for the study, resulting in thirteen research subjects (eight women and five men) being included in the final analysis. They were aged between 27 and 45, and they worked in diverse fields; their professions included communications freelancer, hairdresser-entrepreneur, priest, researcher, restaurant manager, software developing consultant, trainer, web developer and youth worker.

After enrolling in the research, the participants received a list of possible trackers and instructions for the media diary. I contacted them by email or messaging application when they initiated the one-week tracking period to find out how the installation went and during the tracking to ascertain how it was progressing. After the self-monitoring period, the participants were asked to send me their media diary and at least three of the most interesting visualizations from the tracker per device. 
The research interviews were held in locations chosen by the participants or via Skype in the case that a face-to-face meeting was difficult to arrange. Tracker data and media diaries were used as prompts to initiate and facilitate the discussion, as the focus of the research was on the participants' meaning-making practices. The questions in the semistructured interviews started from the use of media devices, moved to the observations from the tracked data and ended with the politics of platforms.

The research data include nearly twelve hours of qualitative interviews, and the prompt material consists of eight media diaries, 218 screenshots of tracker data and two photographs. Each interview was recorded, transcribed and anonymized. I used the same tracking applications as the participants. With this autoethnographic approach, I tried to create conditions for "empathetic knowing" (Pink \& Fors, 2017: 380), which I consider to be central in attempting to create an understanding of people's experiences.

Both the media diary and the research interview were moments in which the selfmonitoring data were interpreted and repurposed. To understand how the self-monitoring data were encountered, the research interviews and media diaries were analysed by qualitative content analysis, tracing the themes that occurred across the empirical data. These themes include gaining confirmation of the appropriateness of ICT use, negotiating the place of ICT devices and evaluations of the tracker. Next, these results are presented in detail.

\section{Encounters with self-monitoring data}

In previous research, it has been shown that the nature of engagement with data visualizations is related to the user's beliefs and opinions as well as his or her interest in the subject matter (e.g., Kennedy et al., 2016). Thus, to contextualize the encounters with the self-tracked data in this research intervention, I begin by looking at the experiential landscapes of intense ICT use into which my participants placed themselves and their motivations to take part in this research intervention.

All of my participants self-identified as being avid ICT users to whom networked media devices and especially social media were an organic part of work and leisure time. The constellations of devices varied. Some of them used primarily smartphones and only rarely, in the occurrence of a special need, a computer. Others relied on their daily use of a complex set of several smartphones, computers, laptops, game consoles, a smart tv and a smart watch. Their relationships with the devices were varied as well, ranging from proudness of belonging to the avant-garde of social media use via a neutral relationship to an anxiety-filled problematic one at the other extreme. Despite these different relations, the participants shared an interest in learning more about the ways in which they use and spend time on digital devices. This curiosity was based on the acknowledgement that ICT devices occupied a significant place in their daily life, almost as if they were attached to their hand, citing youth worker Otto. Two of the participants grounded their motivation on difficulties in handling their use of ICT devices, pointing to a motivation to develop more efficient daily routines. All in all, it can be concluded that the motivations to participate in the research point to a resonance between the research design and the participants' concerns and interests. In previous research, this kind of hope of becoming more mindful has been identified as one of the central ways in which meaning is attributed to data-gathering practices by active self-trackers (Sharon 
\& Zandbergen, 2017)

Despite the motivation to learn more about their ICT use, it has to be noted that a few participants found nothing new or particularly interesting in the data. For example, Maria, currently working in a museum, declared that she did not gain any new insights from the data because she was already aware of her patterns of use. For his part, youth worker Otto lost interest in self-monitoring after the application that he installed continuously failed to record data. Such participant experiences are a good reminder that, despite interest and enthusiasm in the data when initiating self-tracking, the participants might later show indifference, be disappointed or simply not find relevance in the data (see also Ruckenstein, 2014).

\section{Confirmation of appropriate ICT use}

In the tracked data, my participants found a "mirror" to their daily life, which was enriched and facilitated by the networked digital devices. The visualizations of how the devices were used reflected to them the myriad ways in which different applications and web resources were an indispensable part of their daily routines, to the point that they were able to recall what had happened during the day by looking at their ICT use data. For example, in interpreting the tracker data, youth worker Niklas saw when he was at work and when he was spending free time, and priest Sara identified her daily routines as well as events like playing frisbee golf.

In the self-monitoring data, the participants were able to find confirmation that ICT devices and ICTrelated practices occupied a suitable and purposeful place in their daily life. For example, youth worker Olivia was positively surprised when scrutinizing her tracker data. She had anticipated before the research intervention that she was spending more time on Facebook than she regarded as necessary. The smaller than expected amount of Facebook use was a positive surprise, because it confirmed to her that she is using social media in a manner that serves the purpose of her work, that is, spend-

Picture 1. Screenshot of the app usage on Olivia's most used applications

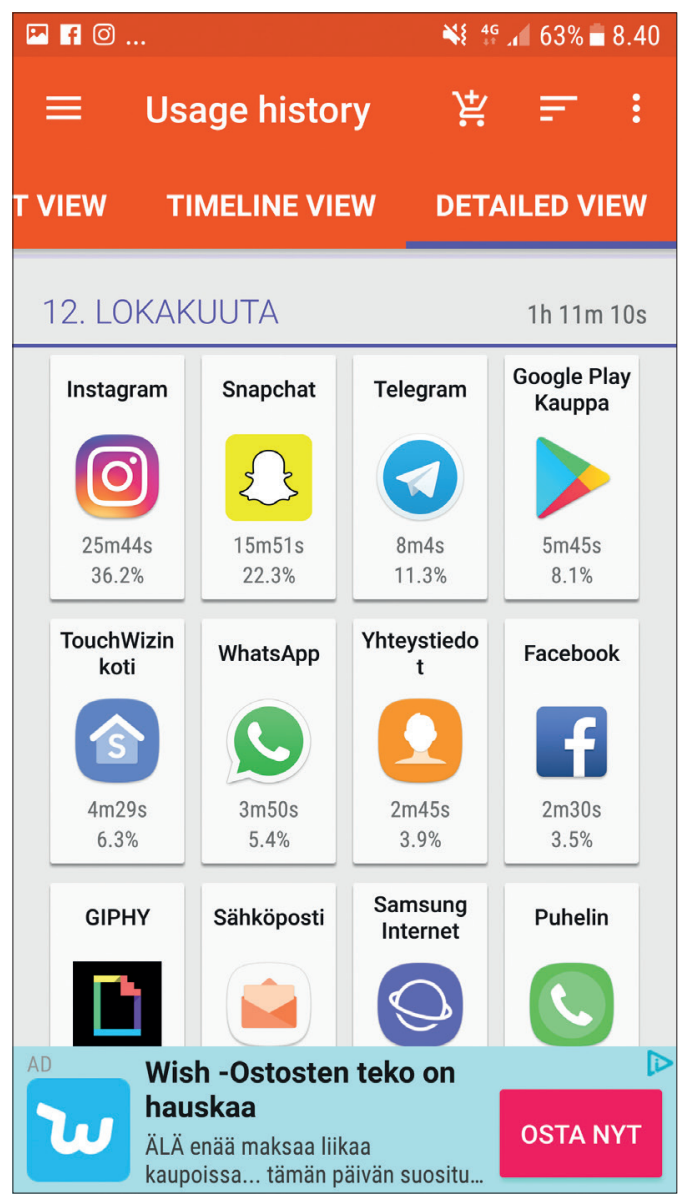


Picture 2. Screenshot from RealizD on the intensities of Sara's smartphone use

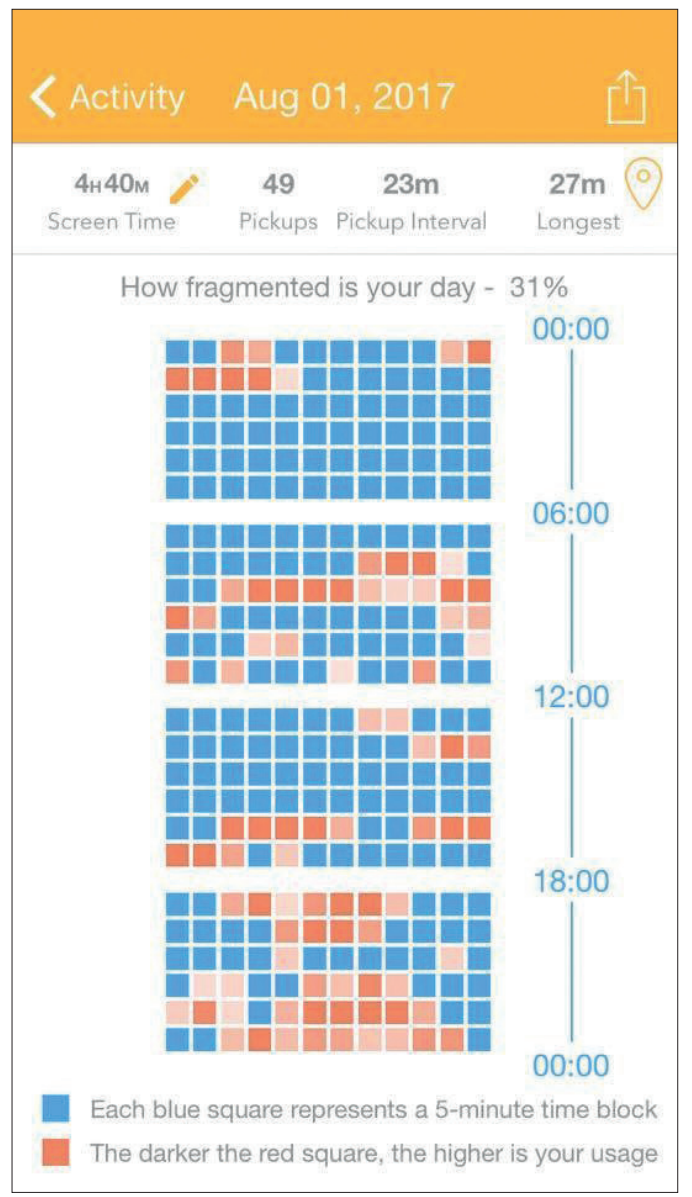

ing time on platforms on which she has the best chances of encountering youths (Picture 1).

For her part, priest Sara was able to grasp the volume of her networked digital devices only when she listed them in her media diary. Observations during the self-monitoring confirmed to her that she had found a practical and convenient way to use all of them in her mundane practices. The encounter with visualizations on the spread of her smartphone use throughout the day helped her to identify and conciliate an aspect of her daily life that had bothered her. Picture 2 is a screenshot from the app used by Sara called RealizD in which the dark red indicates intensive use and the lighter red shorter moments of use.

When I was using this [self-tracking] app I observed that I use my smartphone more when my children are at home and when I'm with them. It is like reaching the top level in guilt. But I also realized and kind of decided during this self-monitoring that I refuse to feel guilty anymore. This is my way of being and living.

Sara's reflections point to the emotional dimensions of datafied life and the normative ideals that frame parenthood and technology use. Having her patterns of smartphone use visualized helped Sara to articulate the place of smartphone use in her hectic daily life with two children under school age. To her, the moments with her smartphone, playing a game or drifting around Facebook between household chores, when putting the children to sleep or when queuing provided relief that helped her to keep calm and have a breather. They were so important to her that she refused to feel guilty about them.

Communication freelancer Anna participated in the research because of her experiences of a negative atmosphere that surrounds intense use of digital technology. As a self-identified pro-technology pioneer, she was fed up of continuously having to counter the moral panic and judging caused by her devoted smartphone use, which to her represented the future for which the society at large was not yet ready. Knowing that social media occupies a significant place in her daily life, she was curious about the actual numbers demonstrating how much she was using different applications. 
Picture 3. Screenshot from Rescue Time on Anna's time spent using different applications

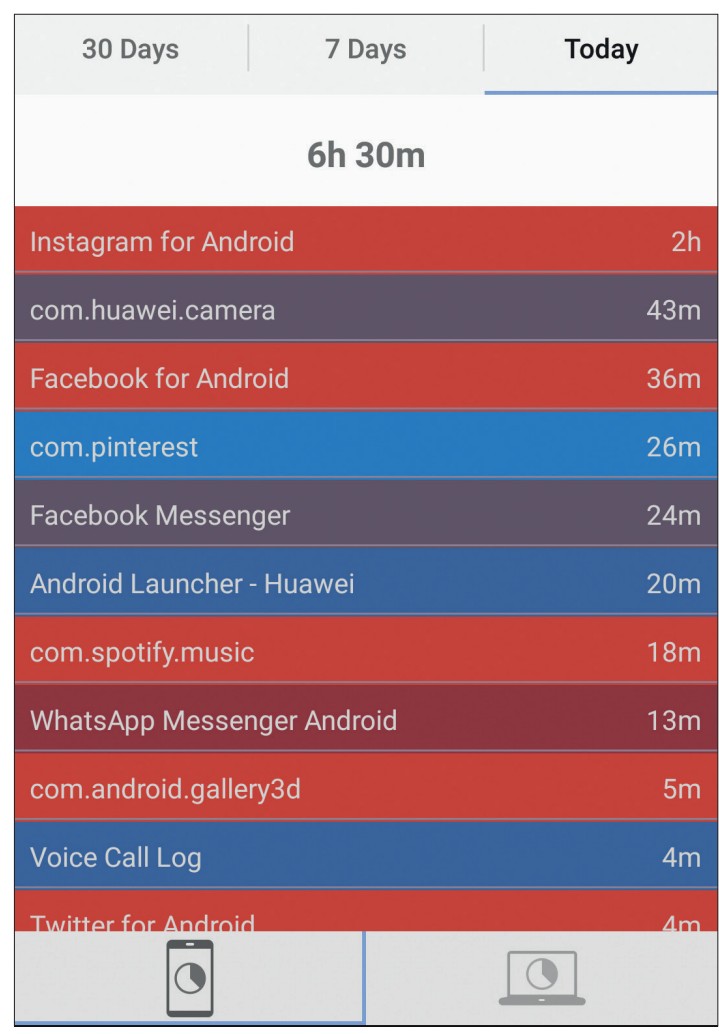

Being proud of her avant-gardist use, she had immediately found practical use for the numbers, demonstrating the personal meanings that people might attach to the data.

I'm interested in the amounts of use, especially because I have had to justify my use so often. I want to turn it into something positive. For example, yesterday, when I was in an interview to initiate collaboration, I told them that I use on average five hours of social media per day. Because it was a social media firm, I thought it was useful for them to know that I'm well aware of what happens in my networks.

\section{Negotiating the place of ICT in daily life}

Besides being a "mirror" of appropriate use, the self-monitoring data pointed to aspects of ICT use that my participants wanted to change. In these cases, the tracked data served as a looking glass showing the unwanted, uncontrollable and burdensome temporal-spatial arrangements propelled by networked digital devices.

In their encounters with the self-monitoring data, some participants were dissatisfied with the way in which ICT devices were temporally situated in their daily life. For example, web designer Daniel identified smartphone use in the morning as a problem and as a habit that he would like to change. For his part, software developing consultant Jesse noticed that he uses the computer equally during the days and evenings (Picture 4).

What I observe here is that my laptop use spreads throughout the day. It makes me think that in the evenings I would like to concentrate on other things than being on the computer.

Both Jesse's and Daniel's reflections on the results of the self-monitoring find resonance in their conflicted relationship with ICT devices that they elaborated in the interview. Daniel had been troubled by spending too much time on devices. He had rearranged his relationship with his devices by taking long breaks from them. The 
Picture 4. Screenshot from ManicTime on Jesse's statistics of computer use

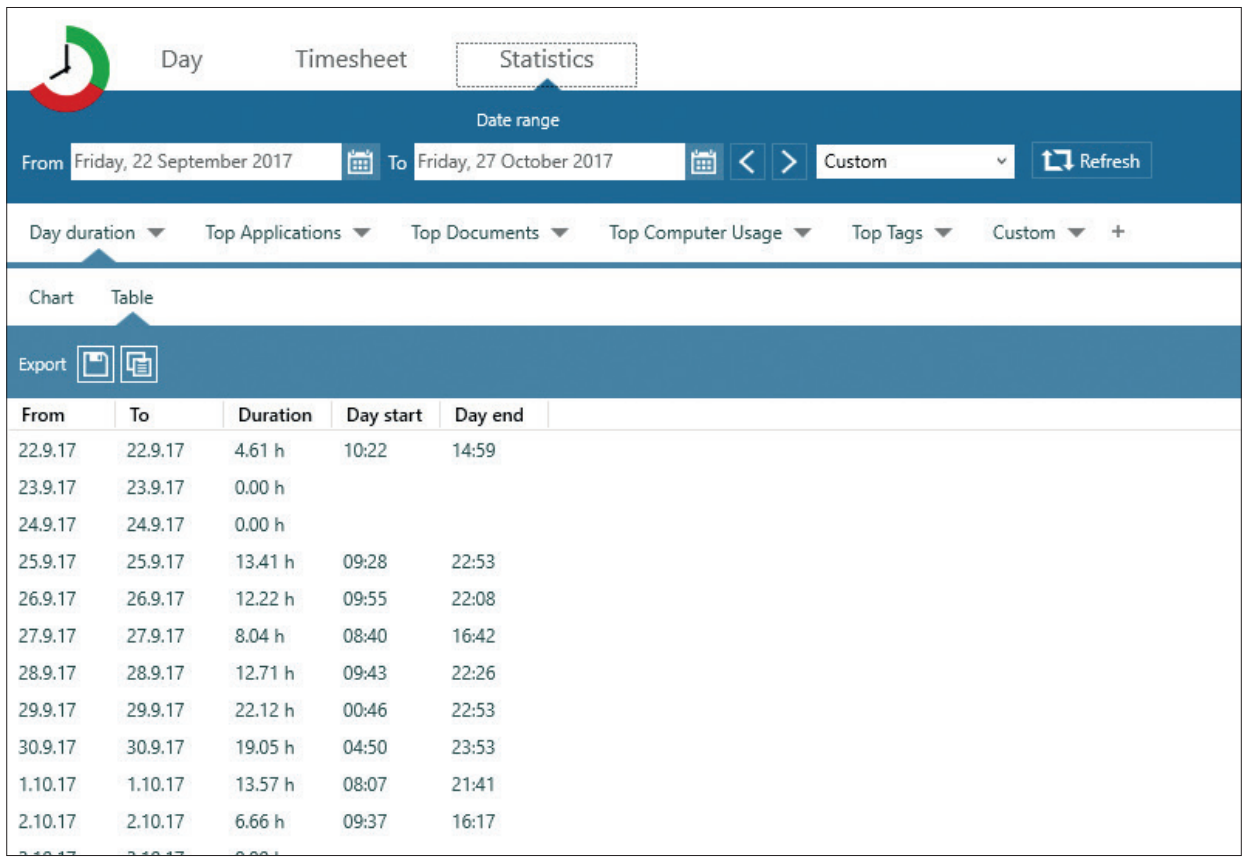

positive experiences from these cuts in his datafied life had inspired him to consider giving up smartphones altogether and switching to a basic model of mobile phone. In Jesse's family, ICT use had been a source of discord. To settle the conflicts caused by abundant ICT use, he and his wife had limited the bedroom and later the dinner table to device-free areas. They had been happy with these limitations, and Jesse's reflections on further limiting ICT use could be interpreted as the next step in the negotiation to reclaim control.

Restaurant manager Leo and hairdresser-entrepreneur Julia were both surprised when encountering the numbers that demonstrated how much they use social media. In examining his data, Leo observed that Facebook usage took a bigger slice of his day than he would prefer. Julia was shocked to see how much time she spent on Facebook. Despite these unpleasant observations, neither of them considered possibilities to alter the situation. Leo explained that he was unable to reduce his use of Facebook, as his job included following his line of business on social media. According to Julia, social media was a necessity in her quotidian life, because "if you aren't in social media, you don't exist". The increased pressure to have a professional online presence compelled her to keep uploading photos to make her work known and to guarantee the visibility of her salon. Quoting her, these social media practices had turned into "social media prostitution" (Picture 5).

Rosa, working as a consultant in a company, shared her conflicted relationship with social media. She was shocked by the amount of time that she spent on her smartphone. The reaction written her media diary points to the emotional responses evoked by the numbers and visualized data (Kennedy \& Hill, 2017). 
Picture 5. Screenshot from RescueTime on Julia's computer use

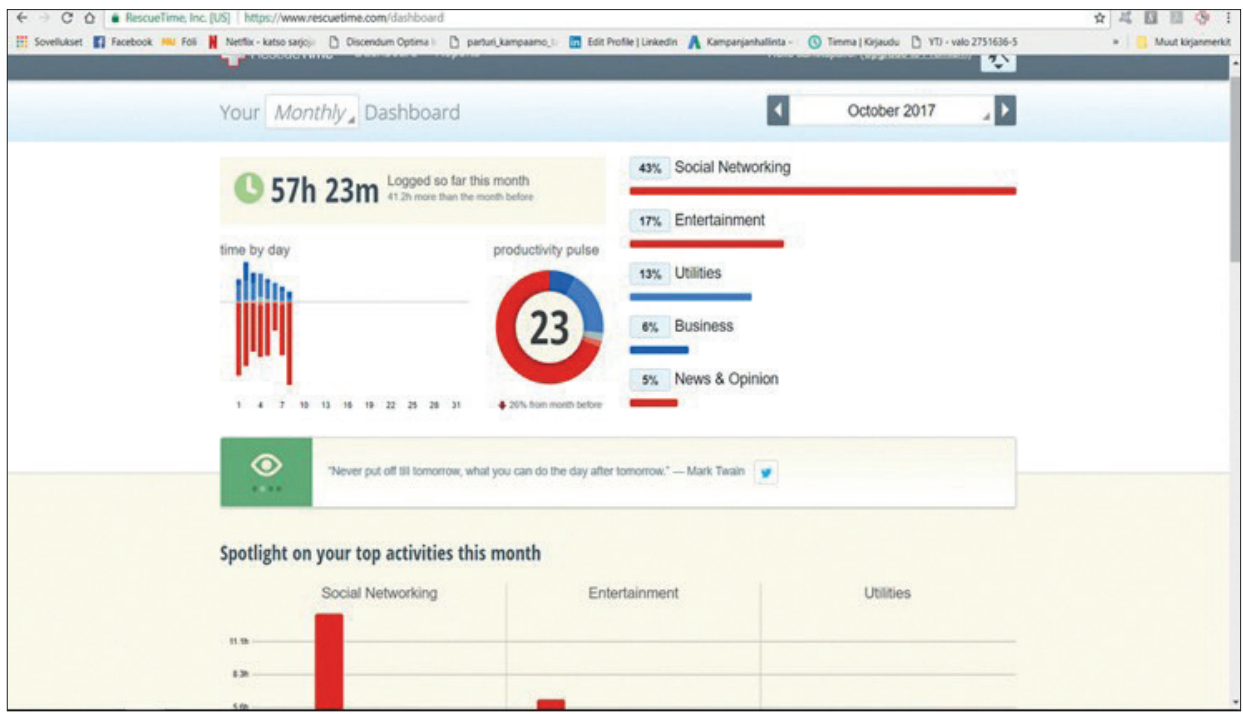

The results are horrendous! Screentime on average 224 min per day $=26$ hours in total per week. At most $6 \mathrm{~h} /$ day. Average interval between pickups $39 \mathrm{~min}$.

In her media diary, she reflected on how she had acquired a habit of using the smartphone as a means to relax. She had realized that it had not been an efficient way to manage stress, as it was intensifying the hook of social media and increasing the amount of untargeted web surfing. She expressed distress over the place that social media had occupied in her life. She was constantly under pressure to produce more content and engage in discussions more intensely, as the contributions made by her active colleagues were so delightful and beneficial. She suffered from guilt about not returning their favour. Previously, she had sought help from a social media consultant to find a balance and functionality in her use. It had been in vain, as the suggested solutions were too time consuming as well. Taking part in the self-monitoring was a chance for her to renegotiate the relationship with her devices. To help her in balancing the use of ICT devices and facilitate her ability to concentrate on what she wanted to do, she installed an application that restricted her access to social media platforms on the phone and computer in the mornings and during work days.

\section{Evaluating the tracker}

In the encounters with the tracked data, the reflections did not solely concentrate on interpreting the numbers. My participants showed skills in data literacy by pondering the meaning-making possibilities that exist in numbers as well as the ideology behind the chosen visualization styles. For example, Sara criticized the style of counting screentime, pickups and pickup intervals in the app RealizD, as she found it to represent an ideology in which checking smartphones is bad. Rosa engaged in similar thoughts, pondering what the number of pickups can actually tell. 
At first, I was shocked by the number [of pickups], but then I was thinking that there are moments when the screen gets locked between use because of the energy saving settings. For example, when I'm cooking, I might unlock the screen five or six times.

For her part, researcher Sofia was irritated by the visualizations of RescueTime, because data were categorized in a way that did not match her type of use. She wrote about her first impressions of the visualizations in her media diary (Picture 6).

For example, LinkedIn and Facebook are marked red in the statistics, that is, as a waste of time. I agree that Facebook to a large degree is a waste, but I regard a LinkedIn profile as a professional "must" and as part of work-related networking.

Picture 6. Screenshot from RescueTime on Sofia's computer

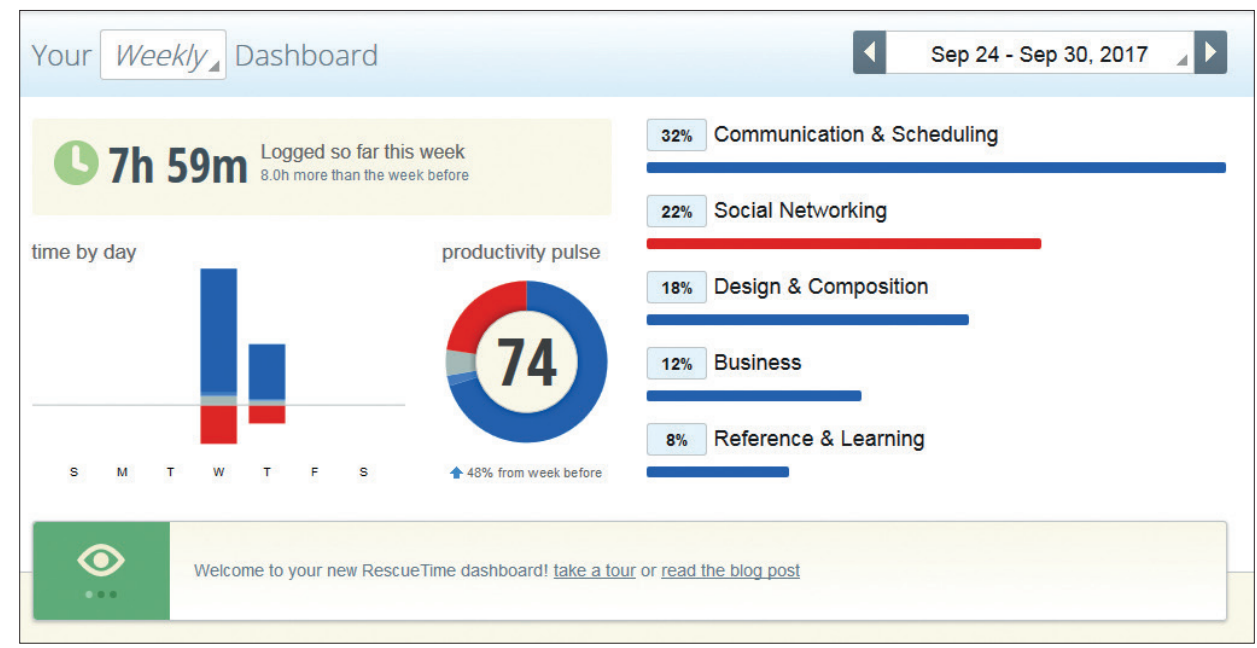

The critical reflections by my participants did not extend from the visualizations to the data-mining practices and the interconnected terms of use of the tracking applications. In this research intervention, the tracking was enabled by freely available software, and the installation of the applications was used as a prompt to find out what the participants thought about data-mining practices and how they experienced being a target of data collection. Most of the participants had accepted the terms of use without even glimpsing them. For them, accepting without reading was a routine that might be "naïve" or "reckless" but was something that is demarcated as an issue not to think about. They associated the data-mining practices of the tracking apps with the data-mining practices that they had become accustomed to in their digital daily use of networked digital devices, applications and websites. As software developing consultant Jesse stated in the interview:

Yeah, Google and Facebook know pretty well who I am, what I like, what I do and what is worth advertising to me. But I have taken a stand that I don't care, because it is very difficult to escape these days. It is easier for me just to let them harvest data and not to stress about it.

The way in which my participants positioned themselves in relation to data mining is in line with what has been observed in previous studies (e.g. Andrejevic, 2014; Best, 2010; Saariketo, 2015; Smith, 2018; Zuboff, 2015). The harvesting of personal informa- 
tion is accepted because it is perceived as something that can be retrieved from other sources anyway, something that it is no longer worth protecting "because the game was lost the day when an account in Facebook was created" or something that might as well be shared as "the data of a middle-aged mother cannot be very interesting to anyone". Especially users who underline their "open-mindedness to technology" enunciated trust in data not being used wrongly or harmfully and underlined their need to take advantage of the possibilities offered by technology despite their terms of use.

\section{Conclusions and reflections on the next steps in future research}

The outcomes of the research intervention open up several possible and intriguing routes for further research and development of tools to enable reflexivity of datafied life. The ways in which people harnessed the tracked data for their own use and found meaning in it seem to be closely attached to their personal lives and concerns. Thus, what was disclosed in the encounters with tracked data were aspects of the dynamics of datafied life that mattered to them. Only rarely did they find something completely surprising in the self-monitoring data. Although there were participants who did not find anything interesting in the data or who lost interest in it during the self-monitoring period, the meanings that most of the participants found in the data point to the relevance and usefulness of gaining access to data that are not usually available.

The results show that media technology is not an invisible part of people's daily routines: they can articulate and reflect its role in their daily life. However, what seems to remain invisible is the sociotechnical power of software and especially the role that data play in "hooking" the users and steering their actions. I suggest that the further development of reflexive mirrors should concentrate on this aspect by connecting two main observations from this research intervention.

Firstly, at the heart of concerns for avid ICT users seems to be the place that social media occupy in their daily life. At the same time, they attest to their usefulness in staying in touch with people and networking but also acknowledge the distractions that they have brought to their daily life. The unpleasant and distressing aspects of social media are captured in labelling them as "wasting time", "loitering", "jamming" and using them "more than one really would like". These experiences resonate with what has been termed "mind hijacking" as part of tech giants' race for attention by critics of contemporary social media (e.g. Lanier, 2018; Lewis, 2017; Smart \& Grundig, 2017; Thompson, 2017). With design choices such as notifications, automatically updating newsfeeds and persuasion to engage with content and share it, users are attracted to spend as much time with the applications as often as possible. As it has been argued in previous research, the continuous flow of data functions as a powerful trigger to bring a user back repeatedly and to be engaged with the software, creating loops of checking (Parviainen, 2016). These design choices remained invisible to the participants, but instead they blamed themselves for poor time management.

Secondly, the way in which my participants positioned themselves in relation to data mining could be interpreted as an illustration of how people have become schooled to ignore the conditions of their mundane software in their routinized use (Thrift \& French, 2002: 311). They were not unaware of the data-mining practices, but either they seemed to care little or they felt powerless to change the situation. Due to the taken for granted- 
ness of data mining and regarding it as a normalized part of using networked devices, it induced few feelings in the participants. This is in heavy contrast to the strong emotions expressed with regard to what is enabled by the data in terms of the "mind-hijacking" design, especially expressed in feelings of losing control as part of social media use.

Thus, I suggest that the next step should be to develop ways to visualize how the harvested data are used to create the personally tailored and persuasive user experiences that induce disruptions to the flows of daily lives and feelings of unease. Such a research design seems especially relevant considering the leak from 2017 revealing that Facebook can identify when users feel insecure or worthless or need a boost of confidence (e.g. Lewis, 2017) and the recent revelations of the systematic data harvesting from Facebook users to target them with personalized advertisements based on their psychological profiles to influence voting (e.g. Cadwalladr \& Graham-Harrison, 2018). A better understanding of these habit-forming and persuasive design practices is needed ever more as markets become infused with increasing numbers of technologies competing for a place in everyday life. The agentive force of visualized data could be powerful in making the complexities more graspable.

\section{Funding}

This work was supported by Academy of Finland [grant no 293549].

\section{Note}

1. In May 2018, Google announced tools for its new Android P operating system to help users better manage their screen time. These features include a more robust do not disturb mode and ways to track app usage under a banner "digital wellbeing". (Lynley 2018). In June 2018, Apple did the same. It announced new controls that allow iOS users to monitor how much time is spent on devices, set time limits on app usage, control the distraction of notifications, and control the device usage for their children (Perez 2018).

\section{References}

Andrejevic, M. (2014). The big data divide. International Journal of Communication, 8: 1673-1689.

Andrejevic, M. \& Burdon, M. (2015). Defining the sensor society. Television \& New Media, 16(1): 19-36.

Bechmann, A. (2015). Managing the interoperable self. In A. Bechmann \& S. Lomborg (eds.), The ubiquitous internet. User and industry perspectives (pp. 54-73). New York \& London: Routledge.

Beer, D. (2009). Power through the algorithm? Participatory web cultures and the technological unconscious. New Media \& Society, 11(6): 985-1002.

Best, K. (2010). Living in the control society: Surveillance, users and digital screen technologies. International Journal of Cultural Studies, 13(1): 5-24.

Cadwalladr, C. \& Graham-Harrison, E. (2018, March 17). Revealed: 50 million Facebook profiles harvested for Cambridge Analytica in major data breach. The Guardian [online]. Retrieved from https://www. theguardian.com/news/2018/mar/17/cambridge-analytica-facebook-influence-us-election [accessed 2018, March 28].

Coté, M. (2014). Data motility. The materiality of big social data. Cultural Studies Review, 20(1): 121-149.

Couldry, N. \& Mejias, U. A. (2018). Data colonialism: Rethinking big data's relation to the contemporary subject. Television \& New Media, 1-14. doi: http://doi.org/10.1177/1527476418796632

Couldry, N. \& Powell, A. (2014). Big data from the bottom up. Big Data \& Society, 1(2): 1-5.

Crawford, K., Lingel, J. \& Karppi, T. (2015). Our metrics, ourselves: A hundred years of self-tracking from the weight scale to the wrist wearable device. European Journal of Cultural Studies, 18(4-5): 479-496.

Fiore-Gartland, B. \& Neff, G. (2015). Communication, mediation, and the expectations of data: Data valences across health and wellness communities. International Journal of Communication, 9: 1466-1484.

Kennedy, H. \& Hill, L. R. (2017). The feeling of numbers: Emotions in everyday engagements with data and their visualisation. Sociology, 1-19, pre-publication. 
Kennedy, H., Hill, R. L., Allen, W. \& Kirk, A. (2016). Engaging with (big) data visualizations: Factors that affect engagement and resulting new definitions of effectiveness. First Monday, 21(11).

Kitchin, R. \& Laurialt, T. (2014). Towards critical data studies: Charting and unpacking data assemblages and their work. Pre-print version of chapter to be published in J. Thatcher, J. Eckert \& A. Shears (eds.), Thinking big data in geography: New regimes, new research. University of Nebraska Press. Retrieved from https://www.researchgate.net/publication/267867447. [accessed 2018, March 27].

Kubitschko, S. \& Kaun, A. (2016). An introduction to innovative methods in media and communication research. In S. Kubitschko \& A. Kaun (eds.), Innovative methods in media and communication research (pp. 1-12). Cham: Palgrave Macmillan.

Lanier, J. (2018). Ten arguments for deleting your social media accounts right now. New York: Henry Holt and Company.

Lewis, P. (2017, October 6). "Our minds can be hijacked": The tech insiders who fear a smartphone dystopia. The Guardian [online]. Retrieved from https://www.theguardian.com/technology/2017/oct/05/smartphone-addiction-silicon-valley-dystopia?CMP=share_btn_fb [accessed 2017, November 4].

Lupton, D. (2016). The diverse domains of quantified selves: Self-tracking modes and dataveillance. Economy and Society, 45(1): 101-122.

Lynley, M. (2018, May 8). Google rolls out app time management controls. TechCrunch [online]. Retrieved from https://techcrunch.com/2018/05/08/android-rolls-out-a-suite-of-time-management-controls-topromote-more-healthy-app-usage/ [accessed 2018, October 16].

Mayer-Schönberger, V. \& Cukier, K. (2013). Big data: A revolution that will transform how we live, work and think. New York: Houghton Mifflin Harcourt.

Michael, M. \& Lupton, D. (2016). Toward a manifesto for the "public understanding of big data". Public Understanding of Science, 25(1): 104-116.

Nafus, D. \& Sherman, J. (2014). This one does not go up to 11: The Quantified Self movement as an alternative big data practice. International Journal of Communication, 8: 1784-1794.

Nguyen, D. H. \& Mynatt, E. D. (2002). Privacy mirrors: Understanding and shaping socio-technical ubiquitous computing systems. Everyday Computing Lab, College of Computing and GVU Center, Georgia Institute of Technology. Retrieved from ftp://130.207.127.123/pub/groups/gvu/tr/2002/2002-2016.pdf. [Accessed 2018, February 18].

Parviainen, J. (2016). Quantified bodies in the checking loop: Analysing the choreographies of biomonitoring and generating big data. Human Technology, 12(1): 56-73.

Perez, S. (2018, June 4). Apple unveils a new set of "digital wellness" features for better managing screen time. TechCrunch [online]. Retrieved from https://techcrunch.com/2018/06/04/apple-unveils-a-new-setof-digital-wellness-features-for-better-managing-screen-time/ [accessed 2018, October 16].

Pink, S. \& Fors, V. (2017). Being in a mediated world: Self-tracking and the mind-body-environment. Cultural Geographies, 24(3): 375-388.

Pybus, J., Coté, M. \& Blanke, T. (2015). Hacking the social life of big data. Big Data \& Society, 2(2): 1-10.

Rooksby, J., Parvin, A., Rost, M., Morrison, A. \& Chalmers, M. (2016). Personal tracking of screen time on digital devices. Paper presented at CHI'16, 2016, May 7-12, San Jose, USA.

Ruckenstein, M. (2014). Visualized and interacted life: Personal analytics and engagements with data doubles. Societies, 4, 68-84.

Saariketo, M. (2015). Neuvotteluja sosiaalisen median arkkitehtuurisesta vallasta. Käyttäjien ja ei-käyttäjien suhtautuminen Facebookiin teknologiavälitteisenä tilana [Negotiations on the architectural power of social media. How users and non-users view Facebook as a technologically mediated space]. Media \& Viestintä, 38(3): 128-146.

Sharon, T. \& Zandbergen, D. (2017). From data fetishism to quantifying selves: Self-tracking practices and the other values of data. New Media \& Society, 19(11): 1695-1709.

Smart, V. \& Grundig, T. (2017, November 3). "We're designing minds": Industry insider reveals secrets of addictive app trade. CBC News [online]. Retrieved from http://www.cbc.ca/news/technology/marketplacephones-1.4384876 [accessed 2017, November 4].

Smith, G. J. D. (2018). Data doxa: The affective consequences of data practices. Big Data \& Society, 5(1): 1-15.

The Economist. (2017, May 6). The world's most valuable resource is no longer oil, but data. [online]. Retrieved from https://www.economist.com/news/leaders/21721656-data-economy-demands-newapproach-antitrust-rules-worlds-most-valuable-resource [accessed 2017, August 14].

Thompson, N. (2017, July 26). Our minds have been hijacked by our phones. Tristan Harris wants to rescue them. Wired [online]. Retrieved from https:/www.wired.com/story/our-minds-have-been-hijacked-byour-phones-tristan-harris-wants-to-rescue-them/ [accessed 2017, November 4].

Thrift, N. (2004). Remembering the technological unconscious by foregrounding knowledges of position. Environment and Planning D: Society and Space, 22: 175-190. 
Thrift, N. \& French, S. (2002). The automatic production of space. Transactions of the Institute of British Geographers, 27(3): 309-335.

Van Dijck, J. (2014). Datafication, dataism and dataveillance: Big data between scientific paradigm and ideology. Surveillance \& Society, 12(2): 197-208.

Zuboff, S. (2015). Big other. Surveillance capitalism and the prospects of an information vivilization. Journal of Information Technology, 30: 75-89. 